\title{
PENERAPAN MODEL DELONE DAN MCLEAN PADA SI-PMB ONLINE DARI PERSPEKTIF PENGGUNA UNTUK MENINGKATKAN KUALITAS LAYANAN
}

\author{
Agustinus Suradi \\ Fakultas Ilmu Komputer \\ Universitas Widya Dharma \\ Email: agustinus@unwidha.ac.id \\ Mariana Windarti \\ Fakultas Ilmu Komputer \\ Universitas Widya Dharma \\ Email: mariana@unwidha.ac.id
}

\begin{abstract}
ABSTRAK
Inovasi strategi pengembangan sistem informasi perlu dikembangkan untuk mendukung kesuksesan dan kualitas layanan sistem penerimaan mahasiswa baru. Masyarakat pengguna sistem informasi penerimaan mahasiswa baru sering mengalami kesulitan ketika mencari informasi yang mereka butuhkan. Tujuan penelitian ini untuk mengidentifikasikan kesuksesan sistem informasi penerimaan mahasiswa baru (SI-PMB) online dan variabel-variabel yang mempengaruhinya. Model DeLone \& McLean IS Success model digunakan dalam penelitian ini, dengan komponen variabel seperti: information quality, system quality dan service quality. Analisis data yang digunakan adalah model struktural dengan alat analisis Partial Least Square (PLS) menggunakan software Smart PLS. Hasil dari penelitian diperoleh hubungan variabel Information Quality $\rightarrow$ User Satisfaction, dengan nilai t statistik 0,324, hubungan variabel Service Quality $\rightarrow$ User Satisfaction, nilai t statistic 2,530, dan hubungan variabel System Quality $\rightarrow$ User Satisfaction, nilai t statistik 3,107, sehingga dapat disimpulkan bahwa terdapat hubungan positif dan siginifikan antara variabel system quality dan user satisfaction, terdapat hubungan positif dan siginifikan antara variabel service quality dan user satisfaction. Hubungan variabel User Satisfaction $\rightarrow$ Net Benefits, nilai t statistik 8,708 menyatakan bahwa ada hubungan positif dan siginifikan antara variabel kepuasan pengguna (user satisfaction) dengan manfaat-manfaat bersih (net benefit).
\end{abstract}

Kata kunci: system quality; information quality; service quality; DeLone dan McLean.

\begin{abstract}
Information systems development strategy innovations need to be developed to support the success and quality of the service system for new student admissions. The information system user community accepts new students the difficulty of improving finding the information they need. The purpose of this study is to identify the success of The online student admission information system (SI-PMB) online and the variables that influence it. The DeLone \& McLean IS Success model is used in this study, with variable components such as: information quality, system quality and service quality. Analysis of the data used is a structural model with the Partial Least Square (PLS) analysis tool using Smart PLS software. The results of this study obtained a relationship between the variable Information Quality $\rightarrow$ User Satisfaction, with a $t$ value of statistics 0.324, the relationship between Service Quality variables User Satisfaction, a t value of statistics 2.530, and the relationship between System Quality variables $\rightarrow$ User Satisfaction, $t$ value of statistics 3.107, it can be concluded that There is a positive and significant relationship between system quality and user satisfaction variables, there is a positive and significant relationship between service quality and user satisfaction variables. The relationship between the User Satisfaction variable $\rightarrow$ Net Benefits, the $t$ value of statistics 8.708 states that there is a positive and significant relationship between the variables of user satisfaction with net benefits.
\end{abstract}

Keywords: system quality; information quality; service quality; DeLone dan McLean.

\section{PENDAHULUAN}

Penerimaan mahasiswa baru merupakan agenda rutin universitas setiap tahun ajaran. Pelayanan informasi Penerimaan Mahasiswa Baru (PMB) ke masyarakat, proses pendaftaran dan administrasi 
seleksi diharapkan memberikan konsep excellent service, cepat, tepat dan akurat. Fungsi pelayanan yang dilakukan lembaga diharapkan mampu mencakup: environmental service, development service, dan protective service.

Dalam rangka meningkatkan kualitas akademis, PMB secara Online telah diterapkan di Universitas Widya Dharma. PMB Online bertujuan memudahkan panitia PMB dalam mengolah data serta mengambil keputusan dan menginformasikan kepada publik. Kondisi tata kelola teknologi informasi sebaiknya menerapkan tata kelola teknologi informasi yang baik.[1].

Standar dimensi kualitas layanan tidak dapat secara langsung diaplikasikan dalam menilai tingkat kualitas layanan PMB Online, karena menunjukan perbedaan dalam proses serta informasi yang di sajikan dalam layanan PMB Online. Definisi dari kualitas layanan Online adalah tingkat dimana sebuah website dapat memberikan fasilitas secara efisien dan efektif dalam melakukan pembelian, penjualan dan pengiriman baik produk maupun jasa.[2]. Pengembangan dimensi yang dilakukan dalam penelitian ini dikaitkan dengan masalah SERVQUAL, ditinjau dari konteks Online melibatkan tiga konstruk dimensi berdasarkan penelitian terhadap kualitas website yang dikenal dengan kualitas website (Website Quality) yang terdiri dari usability, information quality, interaction quality. Kegunaan dianggap lebih berkaitan dengan pola pengguna megenai layanan yang diterima dan interaksi yang dilakukan (perceives vs interact) bukan pada prinsip-prinsip desain situs sendiri.[3].

Beberapa perbandingan standar yang dilakukan yaitu perbandingan antara kenyataan yang ada dengan hasil yang dicapai. Jika pencapaian yang ditunjukan melebihi harapan maka pelanggan akan terpuaskan.[4]. Kualitas layanan merupakan kunci dari ukuran kepuasan. Beberapa studi mengidentifikasi beberapa dimensi kualitas layanan serta indicator yang dimilikinya dengan kepuasan pelanggan. Salah satu yang menjadi instrumen baku dalam menilai kualitas pelayanan adalah Service Quality, meliputi; tangible, responsiveness, reliability, assurance dan empathy.[5].

Dalam penelitian ini variabel kualitas layanan dan kepuasan pelanggan akan dievaluasi, dianalisis dengan menggunakan model DeLone and McLean IS Success model. Dengan adanya peneletian ini dapat dipergunakan sebagai sumber bahan pengembangan sistem informasi penerimaan mahasiswa baru di Universitas Widya Dharma.

\section{METODOLOGI PENELITIAN}

Penelitian ini menggunakan kuisioner sebagai alat untuk memperoleh data primer. Kuisioner dari responden berisi pertanyaan sesuai variabel yang diukur dengan menggunakan skala Likert. Persepsi responden terhadap indikator tersebut diukur dengan skala $1-5$.

\subsection{Variabel Penelitian}

Pada penelitian ini terdapat variabel bebas dan terikat, penelitian dengan konstruk kepuasan pengguna (KP) yang diukur dengan kualitas informasi (KI), kualitas sistem (KS), dan kualitas pelayanan (KPel). Variabel bebas / independent adalah variabel yang akan mempengaruhi variabel lain untuk menerangkan hubungan dengan fenomena yang diobservasi. Dimensi - dimensi yang masuk dalam variabel bebas adalah kualitas informasi, kualitas sistem, dan kualitas layanan. Variabel terikat/ dependent yakni variabel yang dipengaruhi karena adanya variabel bebas. Dimensi dimensi yang masuk dalam variabel ini adalah penggunaan, kepuasan pengguna, dan manfaat.

Variabel System Quality, berfokus pada performa dari sistem, yang mengacu pada seberapa baik kemampuan perangkat lunak, perangkat keras, kebijakan dan procedure dari sistem informasi dapat menyediakan informasi kebutuhan pengguna. Indikator yang digunakan adalah: understandability, accuracy, completeness, system flexibility, security.

Variabel Information Quality, merujuk pada output dari sistem informasi, menyangkut nilai, manfaat, urgensi dan relevansi dari informasi yang dihasilkan. (Pitt dan Watson, 1997). Variabel ini menggambarkan kualitas informasi yang dipersepsikan oleh pengguna yang diukur dengan beberapa indikator yang digunakan Bailey dan Pearson (1983), yaitu: accuracy, timeliness, completeness, relevance, format.

Variabel Service Quality, mengacu pada kualitas yang diharapkan dalam pelayanan sistem informasi. Kualitas ditentukan dalam kepuasan atau ketidak puasan pemakai. Indikator yang digunakan yaitu: Assurance, Reliability, Responsiveness, Tangibles.

Variabel Use, diukur dengan indikator yang digunakan yaitu: intention to use/ actual use, Necesity

Variabel User Satisfaction, indikator yang digunakan yaitu: Efficiency, Effectiveness, Satisfaction

Variabel Net Benefits, hasil dari penggunaan sistem informasi yang memberikan kontribusi positif bagi individu, dan organisasi. Indikator yang digunakan pada variabel ini yaitu : efficiency / effectiveness, productivity. 


\subsection{Sampel Penelitian}

Populasi dan Sampling, penelitian ini dilakukan pada masyarakat pengguna sistem informasi PMB Online Universitas Widya Dharma, yaitu dengan responden para siswa SMTA kelas XII, di beberapa sekolah yang ada di wilayah Karesidenan Surakarta. Sampel atas responden dilakukan dengan judgment sampling.[6]. Judgment sampling adalah teknik pengambilan sampel berdasarkan pertimbangan/ kriteria tertentu melibatkan pemilihan subjek yang berada di tempat yang paling menguntungkan atau dalam posisi terbaik untuk memberikan informasi yang diperlukan, dengan menggunakan rumus Slovin.

$$
n=\frac{N}{1+N e^{2}}
$$

$\mathrm{n}:$ jumlah sampel

$\mathrm{N}$ : jumlah populasi

e : error tolerance

\subsection{Metode Analisis Data}

Analisis statistik yang digunakan adalah model struktural dengan alat analisis Partial Least Square (PLS) menggunakan software SmartPLS 3.0. PLS (Partial Least Square) merupakan model analisis persamaan struktural (SEM) berbasis varian yang secara simultan mampu melakukan pengujian model pengukuran juga sekaligus pengujian model struktural. Berdasarkan tahapan penelitian yang akan dilakukan maka dibuatlah alur penelitian sebagai berikut:

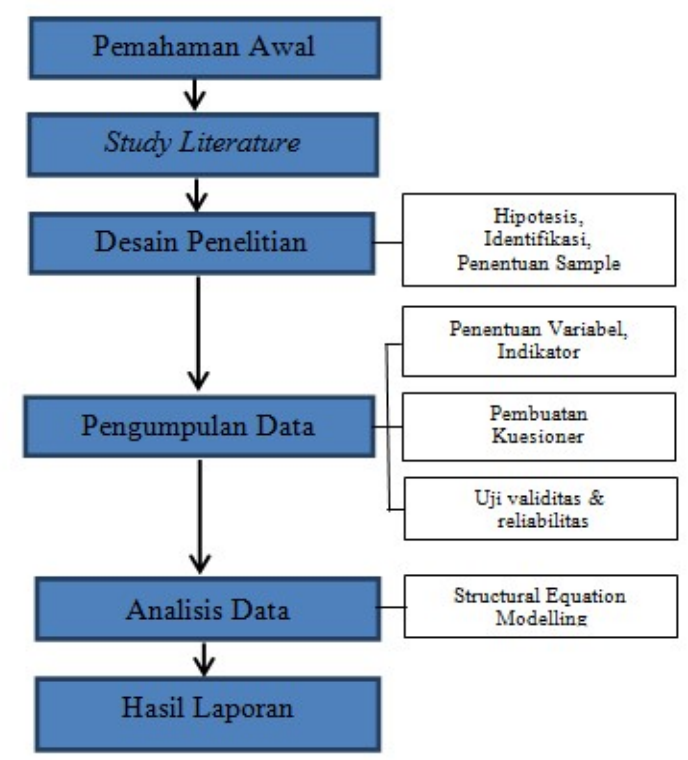

Gambar 1. Alur Penelitian

\section{HASIL DAN PEMBAHASAN}

\subsection{Sampel Populasi}

Tingkat signifikansi $(\alpha)$ menunjukkan probabilitas atau peluang kesalahan yang ditetapkan untuk menolak atau mendukung hipotesis. Sampel dari populasi pada penelitian ini dengan menggunakan tingkat signifikansi $(\alpha)$ ditentukan 5\%. Jumlah sampel populasi dengan tingkat keandalan 95\%, sehingga $\alpha=0,05$.

Jumlah sampel untuk pengisian kuisioner sejumlah 268, dengan ada beberapa data yang kurang lengkap, kemudian disaring dan diambil yang valid sejumlah 223 responden. SMK PS 1 Wonogiri : 26, SMK Muhammadiyah Delanggu: 23, SMK Kristen Pedan Klaten: 19, SMK 1 Veteran Sukoharjo: 51, 
SMK Ganesha Tama Boyolali: 33, SMAN 1 Cawas Klaten: 49, SMKN1 Klaten: 22, Total Responden yang dipakai sejumlah: 223 .

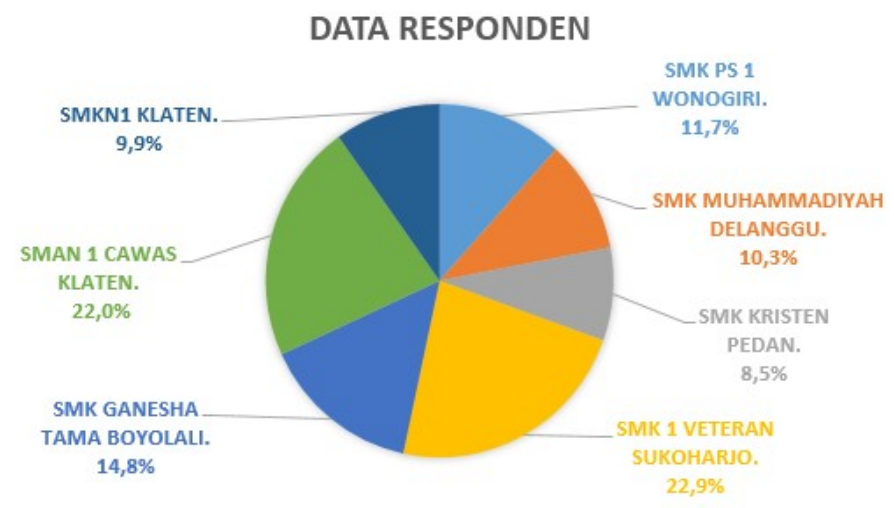

Gambar 2. Data Responden

\subsection{Uji instrumen Penelitian}

Evaluasi model pengukuran merupakan mengukur korelasi antara indikator dengan variabel laten/ konstruk. Dengan mengetahui korelasinya maka akan diketahui validitas serta reliabilitas suatu model. Untuk mengukur validitas dan reliabilitas konstruk, maka dilakukan dengan melihat validitas konvergen, validitas diskriminan, dan reliabilitas konstruk. [7].

Uji validitas

\subsection{Convergent Validity}

Bertujuan agar mengetahui validitas setiap hubungan antara indikator dengan variabel latennya. Convergent validity dari model pengukuran dengan refleksif indikator dinilai berdasarkan korelasi antara construct score dengan component score yang dihitung dengan PLS. Nilai loading yang memiliki tingkat validitas tinggi apabila memiliki nilai faktor loading yang lebih besar dari 0,70 . [7].

Berikut ini disajikan hasil outer loading dengan setiap indikator yang dimiliki oleh setiap variabel laten eksogen dan endogen yang didapat dari olah data dengan menggunakan SmartPLS :

Tabel 1. Outer loadings

\begin{tabular}{|l|r|l|l|l|l|l|}
\hline & $\begin{array}{l}\text { Information } \\
\text { Quality }\end{array}$ & $\begin{array}{l}\text { Net } \\
\text { Benefits }\end{array}$ & $\begin{array}{l}\text { Service } \\
\text { Quality }\end{array}$ & $\begin{array}{l}\text { System } \\
\text { Quality }\end{array}$ & Use & $\begin{array}{l}\text { User } \\
\text { Satisfaction }\end{array}$ \\
\hline IQ1 & 0,914 & & & & & \\
\hline IQ2 & 0,944 & & & & & \\
\hline IQ3 & 0,966 & & & & & \\
\hline IQ4 & 0,957 & & & & & \\
\hline IQ5 & 0,943 & & & & & \\
\hline IU1 & & & & & 0,978 & \\
\hline IU2 & & & & & 0,981 & \\
\hline NB1 & & 0,990 & & & & \\
\hline NB2 & & 0,991 & & & & \\
\hline SQ1 & & & & 0,959 & & \\
\hline SQ2 & & & & 0,969 & & \\
\hline SQ3 & & & & 0,980 & & \\
\hline SQ4 & & & & 0,937 & & \\
\hline SQ5 & & & & 0,957 & & \\
\hline SVQ1 & & & 0,864 & & & \\
\hline SVQ2 & & & 0,907 & & & \\
\hline SVQ3 & & & 0,898 & & & \\
\hline SVQ4 & & & 0,772 & & & \\
\hline US1 & & & & & & 0,975 \\
\hline US2 & & & & & & 0,856 \\
\hline US3 & & & & & & 0,966 \\
\hline
\end{tabular}

Dari hasil di atas semua indikator memiliki muatan (loading) yang lebih besar nilainya dari 0,70 yang menunjukan bahwa semua indikator telah memenuhi syarat validitas konvergen. 


\subsection{Discriminant Validity}

Bertujuan untuk membuktikan bahwa konstruk laten dapat memprediksi ukuran pada blok mereka lebih baik daripada ukuran pada blok lainnya.[7]. Metode untuk menilai discriminant validity dengan melihat akar kuadrat dari AVE untuk setiap konstruk apakah lebih besar dari korelasi antara konstruk dengan konstruk lainnya. Pada model ini memiliki validitas diskriminan yang baik jika akar kuadrat AVE untuk setiap konstruk lebih besar dari korelasi antara dua konstruk di dalam model. Sebelum dibandingkan, terlebih dahulu harus dicari nilai dari AVE untuk masing-masing model. AVE yang baik, disyaratkan oleh [7] memiliki nilai lebih besar dari 0,50. Berikut akan disajikan nilai AVE:

Tabel 2. Average Variance Extraced (AVE)

\begin{tabular}{|l|r|}
\hline & Average Variance Extracted (AVE) \\
\hline Information Quality & 0,893 \\
\hline Net Benefits & 0,982 \\
\hline Service Quality & 0,743 \\
\hline System Quality & 0,922 \\
\hline Use & 0,959 \\
\hline User Satisfaction & 0,872 \\
\hline
\end{tabular}

\subsection{Composite Reliability}

Pengujian lainnya yang dilakukan untuk mengevaluasi outer model dengan melihat reliabilitas konstruk variabel laten yang diukur dengan menggunakan dua kriteria yakni cronbach alpha dan composite reliability dari blok indikator yang mengukur konstruk. Konstruk akan dinyatakan reliabel ketika nilai composite reliability (pc) maupun nilai cronbach alpha diatas 0,70 . Berikut ini hasil ouput dari SmartPLS:

Tabel 3. Composite reliability

\begin{tabular}{|l|r|r|}
\hline & Cronbach's Alpha & \multicolumn{2}{l|}{$\begin{array}{l}\text { Composite } \\
\text { Reliability }\end{array}$} \\
\hline Information Quality & 0,971 & 0,977 \\
\hline Net Benefits & 0,981 & 0,991 \\
\hline Service Quality & 0,883 & 0,920 \\
\hline System Quality & 0,979 & 0,983 \\
\hline Use & 0,958 & 0,979 \\
\hline User Satisfaction & 0,925 & 0,953 \\
\hline
\end{tabular}

Data diolah dengan menggunakan PLS Algorithm disajikan pada gambar dibawah ini.

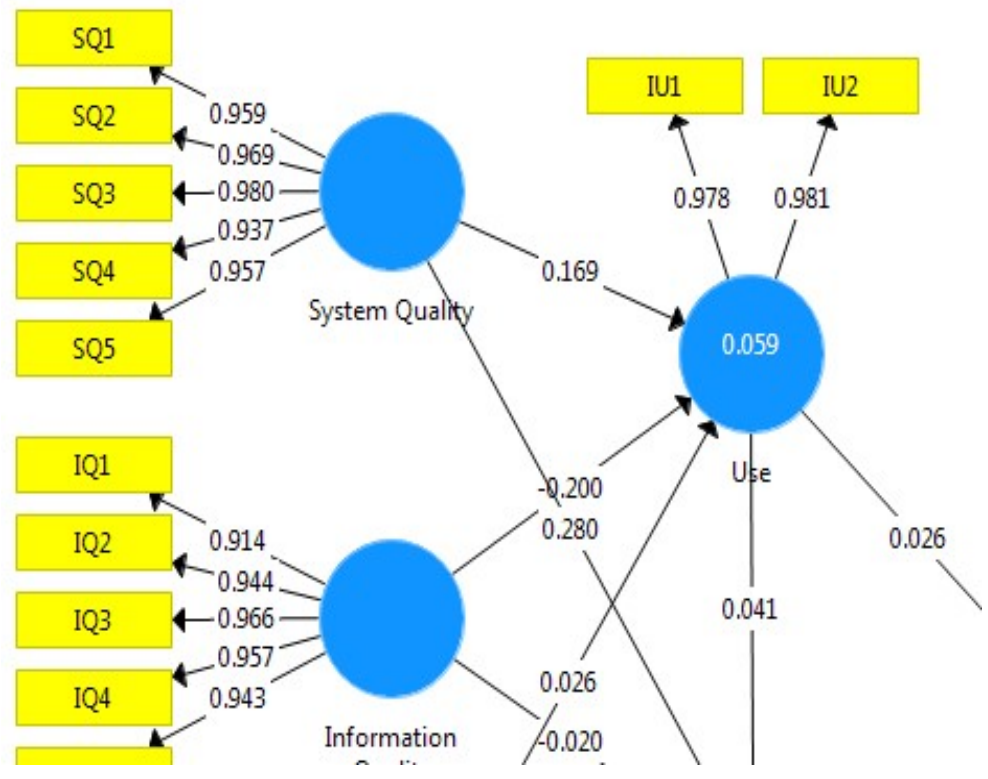




\subsection{Evaluasi Model Struktural}

Mengukur kemampuan prediksi model, yang menggambarkan hubungan antar variabel laten yang dievaluasi, menggunakan empat kriteria yakni koefisien determinasi $\left(\mathrm{R}^{2}\right)$, effect size $(\mathcal{f})$, cross-validated redundancy $\left(Q^{2}\right)$, dan path coefficients.

Tabel 4. $R$ Square

\begin{tabular}{|l|r|r|}
\hline & \multicolumn{1}{|l|}{ R Square } & R Square Adjusted \\
\hline Net Benefits & 0,239 & 0,232 \\
\hline Use & 0,059 & 0,046 \\
\hline User Satisfaction & 0,241 & 0,227 \\
\hline
\end{tabular}

Menentukan nilai inner model dapat ditempuh dengan cara melihat model struktural yang terdiri dari hubungan yang dihipotesiskan di antara konstruk-konstruk laten dalam model penelitian. Dengan menggunakan metode bootstrapping pada SmartPLS, dapat diperoleh kesalahan standar (standard errors), koefisien jalur (path coefficients/ $\beta$ ), dan nilai t Statistik.

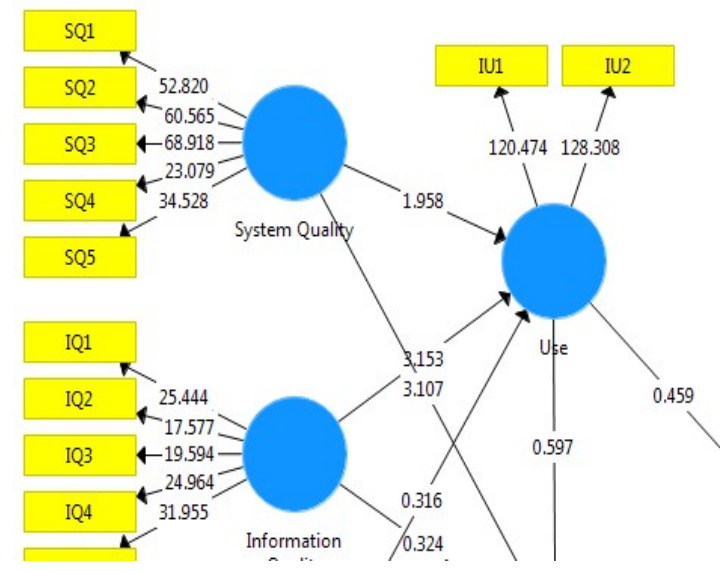

Gambar 4. Path Coefficients

Berikut ini disajikan nilai t statistik penelitian pada tabel di bawah ini.

Tabel 5. Nilai t Statistik

\begin{tabular}{|l|r|r|r|r|r|}
\hline & $\begin{array}{l}\text { Original } \\
\text { Sample } \\
(\mathrm{O})\end{array}$ & $\begin{array}{l}\text { Sample } \\
\text { Mean } \\
(\mathrm{M})\end{array}$ & $\begin{array}{l}\text { Standard } \\
\text { Deviation } \\
\text { (STDEV) }\end{array}$ & $\begin{array}{l}\text { T Statistics } \\
(\text { (IO/STDEV|) }\end{array}$ & $\begin{array}{l}\text { P } \\
\text { Values }\end{array}$ \\
\hline Information Quality $\rightarrow$ Use & $-0,200$ & $-0,209$ & 0,064 & 3,153 & 0,002 \\
\hline Information Quality $\rightarrow$ User Satisfaction & $-0,020$ & $-0,017$ & 0,062 & 0,324 & 0,746 \\
\hline Service Quality $\rightarrow$ Use & 0,026 & 0,019 & 0,084 & 0,316 & 0,752 \\
\hline Service Quality $\rightarrow$ User Satisfaction & 0,242 & 0,240 & 0,096 & 2,530 & 0,012 \\
\hline System Quality $\rightarrow$ Use & 0,169 & 0,179 & 0,086 & 1,958 & 0,051 \\
\hline System Quality $\rightarrow$ User Satisfaction & 0,280 & 0,283 & 0,090 & 3,107 & 0,002 \\
\hline Use $\rightarrow$ Net Benefits & 0,026 & 0,026 & 0,057 & 0,459 & 0,647 \\
\hline Use $\rightarrow$ User Satisfaction & 0,041 & 0,038 & 0,069 & 0,597 & 0,550 \\
\hline User Satisfaction $\rightarrow$ Net Benefits & 0,485 & 0,483 & 0,056 & 8,708 & 0,000 \\
\hline
\end{tabular}

\subsection{Uji Hipotesis}

Prosedur bootstrapping akan menghasilkan nilai t-statistik pada setiap jalur hubungan yang digunakan untuk pengujian hipotesis. Nilai t-statistik ini akan dibandingkan dengan dengan nilai t-tabel. Penelitian yang menggunakan tingkat kepercayaan sebesar 95\% sehingga tingkat presisi atau batas ketidakakuratan $(\alpha)=5 \%=0,05$, nilai nilai t-tabelnya adalah 1,96 . Jika nilai t-statistik didapatkan lebih kecil dari nilai t-tabel ( $\mathrm{t}$-statistik $<1.96$ ), maka $\mathrm{H}_{0}$ diterima dan $\mathrm{H}_{1}$ ditolak. Jika nilai t-statistik didapatkan lebih besar atau sama dengan t-tabel ( $\mathrm{t}$-statistik > 1.96 ), maka $\mathrm{H}_{0}$ ditolak dan $\mathrm{H}_{1}$ diterima.[8]. 
Hasil pengujian hipotesis dapat diperoleh dengan menjalankan program dengan Bootstrapping. Hipotesis $\mathrm{H}_{1}$ diterima apabila memiliki nilai t-statistik lebih dari 1,96. Berdasarkan hasil pengujian disusun hipotesis sebagai berikut:

1. Kualitas sistem terhadap penggunaan sistem.

Hubungan antara System Quality $\rightarrow$ Use, nilai t statistik 1,958 menyatakan menolak hipotesis $\mathrm{H}_{1(1)}$, dan menyimpulkan bahwa $\mathrm{H}_{0(1)}$ : Tidak ada hubungan positif dan siginifikan antara variabel system quality dengan penggunaan use.

2. Kualitas sistem terhadap kepuasan pengguna.

Hubungan antara System Quality $\rightarrow$ User Satisfaction nilai t statistik 3,107 menyatakan menerima hipotesis, dan menyimpulkan bahwa $\mathrm{H}_{1(2)}$ : Ada hubungan positif dan siginifikan antara variabel system quality dengan user satisfaction.

3. Kualitas informasi terhadap penggunaan sistem.

Hubungan antara Information Quality $\rightarrow$ Use nilai t statistik 3,153 menyatakan menerima hipotesis, dan menyimpulkan bahwa $\mathrm{H}_{1(3)}$ : Ada hubungan positif dan siginifikan antara variabel information quality dengan use.

4. Kualitas informasi terhadap kepuasan pengguna.

Hubungan antara Information Quality $\rightarrow$ User Satisfaction nilai t statistik 0,324 menyatakan menolak hipotesis $\mathrm{H}_{1(4)}$, dan menyimpulkan bahwa $\mathrm{H}_{0(4)}$ : Tidak ada hubungan positif dan siginifikan antara variabel information quality dengan user satisfaction.

5. Kualitas layanan terhadap penggunaan.

Hubungan antara Service Quality $\rightarrow$ Use nilai t statistik 0,316 menyatakan menolak hipotesis $\mathrm{H}_{1(5)}$, dan menyimpulkan bahwa $\mathrm{H}_{0(5)}$ : Tidak ada hubungan positif dan siginifikan antara variabel service quality dengan use.

6. Kualitas layanan terhadap kepuasan pengguna.

Hubungan antara Service Quality $\rightarrow$ User Satisfaction nilai t statistik 2,530 menyatakan menerima hipotesis, dan menyimpulkan bahwa $\mathrm{H}_{1(6)}$ : Ada hubungan positif dan siginifikan antara variabel service quality dengan user satisfaction.

7. Penggunaan sistem terhadap kepuasan pengguna.

Hubungan antara Use $\rightarrow$ User Satisfaction nilai t statistik 0,597 menyatakan menolak hipotesis $\mathrm{H} 1(7)$, dan menyimpulkan bahwa $\mathrm{H}_{0(7)}$ : Tidak ada hubungan positif dan siginifikan antara variabel use dengan user satisfaction.

8. Penggunaan terhadap manfaat-manfaat bersih.

Hubungan antara Use $\rightarrow$ Net Benefits nilai t statistik 0,459 menyatakan menolak hipotesis $\mathrm{H}_{1(8)}$, dan menyimpulkan bahwa $\mathrm{H}_{0(8)}$ : Tidak ada hubungan positif dan siginifikan antara variabel use dengan net benefit.

9. Kepuasan pengguna terhadap manfaat-manfaat bersih.

Hubungan antara User Satisfaction $\rightarrow$ Net Benefits nilai t statistik 8,708 menyatakan menerima hipotesis, dan menyimpulkan bahwa $\mathrm{H}_{1(9)}$ : Ada hubungan positif dan siginifikan antara variabel user satisfaction dengan net benefit.

Dari hasil nilai t statistic diperoleh bahwa: Information Quality $\rightarrow$ User Satisfaction, nilai t statistik 0,324, Service Quality $\rightarrow$ User Satisfaction, nilai t statistik 2,530, System Quality $\rightarrow$ User Satisfaction, nilai t statistik 3,107, maka dapat ditarik kesimpulan bahwa kepuasan pengguna didukung secara signifikan oleh kualitas layanan dan kualitas sistem.

Berdasarkan hasil nilai t statistik bahwa : User Satisfaction $\rightarrow$ Net Benefits, nilai t statistik 8,708 menyatakan bahwa ada hubungan positif dan siginifikan diantara variabel user satisfaction dengan net benefit.

\section{DAFTAR PUSTAKA}

[1] A. Suradi dan S. Wiyanta, "Penerapan Framework COBIT untuk Identifikasi Tingkat Kematangan Tata Kelola Teknologi Informasi: Studi Kasus di Fasilkom Unwidha,” Khazanah Inform., vol. 3, no. 1, hal. 38-42, 2017.

[2] Parasuraman dkk., "E-S-QUAL A Multiple Item Scale for Assessing Electronic Service Quality," vol. 7, no. X, hal. 1-21, 2005.

[3] S. J. Barnes dan R. T. Vidgen, "Assessing e-commerce quality with WebQual: An evaluation of the usability, informaton quality, and interaction quality on Internet bookstores," J. Electron. Commer. Res., vol. VOL. 3, NO, 2002.

[4] P. D. K. L. K. Kotler, Manajemen Pemasaran, Edisi Kedu. Indeks : Jakarta, 2007. 
[5] B. Parasuraman, A., V.A., Zeithml dan L.L., "SERVQUAL : A Multiple Item Scale for Meansuring Consumer Perseption of Service Quality," J. Retail., hal. 64, 1998.

[6] Uma Sekaran, Research Methods For Business/ Metodologi Penelitian untuk Bisnis, Edisi 4. Salemba Empat, Jakarta, 2006.

[7] I. Gozali, Structural Equation Modeling Metode Alternatif dengan Partial Least Square, Edisi 2. Semarang: Badan Penerbit Universitas Diponegoro, 2008.

[8] I. GHozali dan H. Latan, Partial Least Squares, Konsep Teknik dan Aplikasi Menggunakan Program SmartPLS 3.0 Untuk Penelitian Empiris, Edisi 2. Semarang: Badan Penerbit Universitas Diponegoro Semarang, 2015. 